\title{
Estaciones de un diálogo para seguir pensando
}

\section{(1) Hilda Sabato}

Programa PEHESA, Instituto Ravignani, CONICET / Universidad de Buenos Aires, Argentina

Correo electrónico: sabatohilda@gmail.com

\section{Resumen}

Estas notas reflexionan acerca de los temas planteados en los comentarios a mi libro Repúblicas del Nuevo Mundo. El experimento político latinoamericano del siglo XIX (Buenos Aires/Lima/Santiago de Chile: Taurus, 2021) por los historiadores Daniel Gutiérrez Ardila, Erika Pani, Darío Roldán y Sol Serrano. Refieren a diferentes aspectos de la vida política en las repúblicas hispanoamericanas de esa centuria así como a la historiografía sobre esa amplia temática.

Palabras clave: Repúblicas, Política, Hispanoamérica, Siglo XIX.

\section{A step in an ongoing dialogue}

\begin{abstract}
This piece reflects upon several of the themes raised by historians Daniel Gutiérrez Ardila, Erika Pani, Darío Roldán, and Sol Serrano in their comments to my book Repúblicas del Nuevo Mundo. El experimento político latinoamericano del siglo XIX (Buenos Aires/Lima/Santiago de Chile: Taurus, 2021). It focuses on the political life of the Spanish American republics during that century and on the historiography thereof.


Después de leer los cuatro ensayos que preceden estas líneas no tengo sino palabras de agradecimiento para Daniel Gutiérrez Ardila, Erika Pani, Darío Roldán y Sol Serrano por sus generosos y agudos comentarios, que me incitan a seguir reflexionando sobre la historia que quise contar en Repúblicas del Nuevo Mundo. También agradezco al equipo editor del Boletín del Instituto Ravignani por la iniciativa de generar este diálogo.

Estos ensayos abordan el libro desde diferentes ángulos a la vez que van trazando caminos paralelos de indagación. Hay, en primer lugar, un esfuerzo por ubicar mi producción en el marco de la historiografía y los debates actuales, desde donde se desprenden varias líneas de interrogación. Todos ellos indagan, además, en algunas de las temáticas centrales de mi libro, donde también afloran preguntas sustantivas. Finalmente, plantean problemas que, a la vez que trascienden el marco deliberadamente acotado que me impuse al escribir este texto, abren una variedad de cuestiones clave para analizar las repúblicas decimonónicas y para seguir pensando. En lo que sigue, intentaré desgranar algunas reflexiones inspiradas por los comentarios de mis colegas, aunque sin pretender cubrir, y mucho menos agotar, los temas que surgen de estos sugerentes escritos.

\section{Caminos de la historiografía}

Comienzo con una disculpa: Sol Serrano me pregunta por "los lugares recorridos", por los caminos historiográficos que desembocan en esta obra -un interrogante movilizador que sin embargo voy a eludir sin excusas. En cambio, retomo una referencia que aparece en el libro y recuperan todos los comentarios: su escritura solo fue posible porque existe una vasta, diversa y original bibliografía sobre la historia política de América Latina del siglo XIX, escrita sobre todo a partir de la década de 1980 y de la cual forman parte también mis trabajos anteriores. No vale la pena que acá vuelva sobre los orígenes, las influencias, los alcances y las limitaciones de esa producción, que ha sido y sigue siendo objeto de análisis volcados en muy diversas publicaciones, como bien señala Erika Pani en su reseña. Al mismo tiempo, toda esa literatura se inserta en un movimiento mayor de puesta en cuestión de los paradigmas teóricos y metodológicos que habían dominado la historiografía de las décadas anteriores, y allí sin duda jugaron un papel importante las objeciones al estructuralismo, que menciona Serrano, entre otras operaciones críticas. En ese sentido, el libro también es deudor de esos y otros debates planteados en el seno de la teoría social y la filosofía política, además de la historiografía.

Pero Repúblicas del Nuevo Mundo no es apenas una síntesis de lo ya dado, como también señalan los comentarios, pues define un objeto propio (el experimento político republicano en Hispanoamérica) y una manera sui generis de abordarlo para llegar a una interpretación de largo plazo de esa experiencia, que incluye una mirada comparativa hacia otros ensayos de república en la misma época. En ese sentido, sin duda mi recorrido intelectual particular ha debido incidir en la operación de conocimiento que propongo, pero -como ya advertí- aquí no voy a incursionar en ese terreno. 
Sol Serrano formula también otra pregunta muy provocadora y para la cual tampoco tengo una respuesta, referida a la ausencia de América Latina "de las grandes narrativas sobre las revoluciones modernas”. En ese punto, coincido con sus hipótesis respecto a esa vacancia, que sin embargo requeriría una exploración específica. Se podría aventurar que en el siglo XIX el lugar subordinado que ya ocupaba España en el concierto de las naciones se reflejara en el escaso interés que despertaron sus colonias en la reflexión de época, como sugiere Serrano. Al mismo tiempo, a pesar de su marginalidad relativa, eran territorios codiciados en las disputas inter-imperiales como piezas en un tablero hegemonizado por las principales potencias del momento, que a su vez atrajeron a viajeros, naturalistas, comerciantes y aventureros de toda laya. En ese contexto, la inserción de estas tierras en el "ciclo revolucionario" mencionado por Roldán se inició con un gesto radical en el Saint-Domingue entonces bajo mandato francés, que excedió los marcos en que se buscaba encarrilar la modernidad atlántica. Y aunque la descolonización posterior siguió caminos menos amenazantes, se afirmó a contrapelo del giro moderado y conservador europeo, al menos hasta la década de 1830.

Las guerras de independencia, las incertidumbres territoriales, y las violentas confrontaciones políticas posiblemente reforzaran la visión de Hispanoamérica poscolonial como una región ajena a los parámetros pretendidamente civilizados del orden alcanzado después del Congreso de Viena. Pero quizá por eso mismo resultara atractiva para un conjunto variopinto de librepensadores europeos socialistas románticos, utópicos, republicanos, entre otros-, muchos de los cuales, perseguidos por sucesivas olas represivas en sus países de origen, se exiliaron en tierras americanas y apostaron a los horizontes de libertad que esperaban encontrar en ellas para labrar un futuro mejor. Esa evaluación encontraba eco en la propia Hispanoamérica, donde las duras críticas a la situación de las naciones en formación convivía con convicciones muy arraigadas respecto al potencial liberador e igualitario de estas repúblicas frente a la falta de dinamismo de una Europa anclada en la tradición y el viejo orden. El balance era complejo y, por décadas, los Estados Unidos en el norte marcaron un camino que no parecía tan alejado de los derroteros posibles para el sur.

Pero en algún momento esa percepción de trayectorias hacia la modernidad paralelas aunque desfasadas en el tiempo, fue perdiendo vigencia frente diagnósticos que descartaban la posibilidad misma de ese tránsito. Así, para el siglo XX cobró fuerza la sentencia de "la imposibilidad de la modernidad" en América Latina, ya para lamentar ese destino que condenaba a estas tierras al atraso, ya para como bien señala Sol Serrano- celebrar la resistencia de las sociedades locales a la impostura de valores e instituciones ajenas a sus tradiciones, que solo habrían servido para asegurar la dominación de las elites asociadas al imperialismo en expansión. Estas derivas han sido estudiadas por la historia intelectual, pero aquí las evoco porque tuvieron una decisiva influencia sobre las maneras de leer el siglo XIX. En sintonía con esa visión, que atravesó las interpretaciones de los locales pero también de los analistas externos, se impuso una mirada sobre el pasado latinoamericano que clausuraba la posibilidad misma de analizar los procesos de revolución, independencia y descolonización como parte de la historia más amplia 
de cambio político iniciado por el ciclo revolucionario atlántico. Y se acuñaron las conocidas imágenes de una modernidad fallida, del fracaso del liberalismo y del artificio de la república. A desmontar esas barreras se han dedicado los esfuerzos de buena parte de la historiografía latinoamericana de las últimas décadas, con resultados muy originales en cuanto a la revisión del pasado de la región, pero efectos relativamente limitados a la hora de incidir sobre los debates globales. Será cuestión de seguir insistiendo...

\section{Paralelos y contrastes}

En relación con la inserción de las novísimas repúblicas en ese marco más global, el libro avanza un paso más allá de esa constatación para aventurar algunos paralelos y contrastes con otras experiencias republicanas contemporáneas, en particular la de los Estados Unidos y los más destacados -aunque efímeros o tardíos- casos europeos. Este punto ha sido resaltado en todos los comentarios, que suman nuevos interrogantes y consideraciones a mis hipótesis tentativas y alimentan el debate. Más que avanzar en esa dirección, quisiera detenerme en una cuestión previa, el porqué de esos intentos de tipo comparativo.

No estaba en mis planes iniciales incursionar más allá de la región, pero pronto se me impuso la necesidad de mirar estas repúblicas como parte de un cambio político que las excedía y que incluía en los mismos años otros experimentos similares, exitosos o frustrados, en el resto del mundo. La consulta de una rica literatura sobre esas otras historias - de una historiografía que también se renovaba- me convenció de que los problemas políticos que encontraba para Hispanoamérica estaban en sintonía con los de otras sociedades embarcadas en lo que llamé la "aventura republicana". Las dificultades para instaurar comunidades políticas sobre la base de la soberanía popular en clave republicana parecían replicarse en todas partes y exigir de los protagonistas enormes esfuerzos para generar instancias de creación y legitimación del poder en base a los nuevos principios y para dotarlas de cierta estabilidad que garantizara su reproducción relativamente pacífica y su continuidad en el tiempo. El caso que tenía entre manos no era, por lo tanto, excepcional, aunque no podía tampoco disolverse como un ejemplo más de un patrón universal. En realidad, no hay tal patrón universal, y si bien es posible detectar problemas comunes, estos se despliegan en sociedades muy diferentes, que exploraron soluciones diversas para enfrentar dificultades semejantes; algunas de ellas, como los ejemplos americanos, del norte y del sur, para insistir en la república -en muy diversos formatos- y otras, para explorar otros derroteros políticos.

Con ese diagnóstico, más que comparar estrictamente con otras realidades, me propuse tenerlas como referencia, como imágenes de alternativas posibles que me permitieran ponderar lo que era propio de nuestras repúblicas y lo que, en cambio, formaba parte de un repertorio compartido. No se trataba, por lo tanto, de hacer un cuadro de similitudes y diferencias o de explorar a fondo el porqué de unas y otras, sino apenas trazar paralelos y distancias en un terreno muy específico, el 
de las relaciones entre pueblo y gobierno forjadas al calor del sistema representativo, que es -claro está- el foco de todo el libro. Queda pendiente, por lo tanto, la enorme tarea de pensar esas experiencias en conjunto. La posibilidad de tomar América en su totalidad, como sugiere Erika Pani, constituye un desafío muy tentador, quizá menos inalcanzable que la inmersión que propone Darío Roldán en el heterogéneo y múltiple "experimento político" de la Europa decimonónica. En un artículo reciente, Clément Thibaud ofrece otro recorte posible al postular la necesidad de un análisis "descentrado" del republicanismo moderno, que tome al mundo atlántico en toda su diversidad, incluyendo América del norte y del sur, Europa occidental y mediterránea y parte del África (Thibaud, 2019). Estamos, pues, frente a desafíos historiográficos apasionantes que trascienden los estrechos límites del libro en consideración.

\section{Lo que no está}

Esos límites no son solo geográficos. La propuesta de analizar las muy diversas experiencias de formación de nuevas comunidades políticas en Hispanoamérica poscolonial y sus cambios a lo largo de casi un siglo fue el resultado de un proceso previo de exploración sistemática de lo ya conocido y de ensayos de aproximación a lo que iba encontrando. Hubo un supuesto de partida, que orientó mis indagaciones: me encuentro entre quienes consideran la política como instancia productiva de la vida colectiva, que no es reductible a otras esferas del quehacer humano. En ese sentido, entiendo que es posible analizar específicamente esa dimensión que, aunque se articule en cada momento y lugar con otras y no pueda, por lo tanto, considerarse stricto sensu como autónoma, no se deriva necesariamente de ninguna de ellas. En el caso que nos ocupa, este presupuesto resulta particularmente pertinente, en la medida que esta historia se inicia con una decisión fundamental en sede política, la de fundar nuevas comunidades sobre el principio de la soberanía popular en clave republicana, que tuvo efectos instituyentes y fue la base para la creación de lo nuevo.

Ese punto de partida común pronto dio lugar, sin embargo, a una diversidad de experiencias concretas, tanto a través del tiempo como del espacio. Ante ese panorama imposible de reducir a la unidad, me sorprendí al descubrir que era posible distinguir rasgos y tendencias comunes, en particular en relación con aquello que remitía a la institución misma de la nueva vida en común:la invención del pueblo y la instauración del sistema representativo para responder a los desafíos que planteaba la vigencia de la soberanía popular como fuente única de poder en la república. Así, fui notando ciertos patrones compartidos en las normas, instituciones y prácticas en toda la geografía hispanoamericana, cuyas variaciones en el tiempo también seguían pautas muy semejantes. Tres instancias aparecían como pilares fundamentales en la relación entre pueblo y gobierno en las flamantes repúblicas -las elecciones, la ciudadanía armada materializada en las milicias y la opinión pública- y a ellas dediqué, como advierten los comentaristas, los capítulos centrales de mi libro. La vigencia de esas instancias de participación 
popular y de relación entre los de "arriba" y los de "abajo" marcaron de manera decisiva la vida política, que por cierto no se reducía a ellas pero que no puede entenderse sino atendiendo a sus características y variaciones. Así es que en el último capítulo arriesgo una interpretación de cómo, sobre esa base, se fueron moldeando las formas de hacer política en estas repúblicas, con rasgos propios a la región y al período que ubico entre la segunda y la octava décadas del siglo. En particular, busco mostrar hasta qué punto ciertas características -como la inestabilidad política, el personalismo en las dirigencias, o el recurso a la violencia, entre otros- que muy habitualmente se han asociado a la "imposibilidad de la modernidad" en Hispanoamérica y se exhiben como pruebas de un liberalismo "fallido" pueden entenderse, en cambio, como resultados del propio experimento republicano, de sus valores e imperativos anclados en la modernidad, y de las formas que fue adoptando para abrirse paso frente a los desafíos que planteó, en todos lados, la decisión de fundar la comunidad política y el poder sobre principios inmanentes, alejados de toda trascendencia.

Queda claro, sin embargo, que esta aproximación al "experimento político latinoamericano" no pretende cubrir la historia de esas repúblicas decimonónicas en su totalidad ni dar cuenta de todos los problemas que hubieron de enfrentar tanto en el terreno político como en otras dimensiones de esa experiencia social heterogénea y cambiante. En ese sentido, recupero las agudas observaciones de los comentaristas que apuntan a destacar aspectos desatendidos en mi libro pero que hay que introducir a la hora de pensar de manera más integral los procesos políticos que atravesaron nuestros países.

Así, Gutiérrez Ardila sostiene que para "dar cuenta de la volatilidad política" de esas repúblicas habría que considerar al menos tres cuestiones, a las que luego agrega una cuarta que abordaré más abajo. Entre las primeras, se detiene en la "baja densidad demográfica y la extensión" agravadas por la precariedad de las comunicaciones y en lo que llama "la morosidad económica" que resultó un freno a aspiraciones y realizaciones. Estos son, sin duda, factores de peso a la hora de analizar los problemas políticos de la región, pero que trascienden los límites que le impuse a mi indagación. La tercera cuestión, en cambio, se articula estrechamente con lo que desarrollo en el libro pues remite a un permanente estado de experimentación en materia republicana que se observa en todo el período, suscitado por diversos factores internos y externos. No me convence demasiado, sin embargo, la figura de la "paranoia" que utiliza Gutiérrez Ardila, sobre todo cuando se refiere a lo que llama "las ambiciones monocráticas" de los dirigentes, pues estas aparecen así como un factor externo a la propia dinámica política que vendría a perturbar las reglas del juego. Desde la perspectiva que desarrollo en el libro, en cambio, la concentración del poder en una persona (un "caudillo") y sus "ambiciones de perpetuarse" en él, no resultaban ajenas a la dinámica republicana; más aún, la dictadura presumiblemente "a la romana" fue invocada precisamente para dar estabilidad a la república en tiempos de gran incertidumbre y conflicto. El hombre fuerte operaba así como un contrapeso a la volatilidad, lo que no impedía que despertara a su vez reacciones que podían alentar la inestabilidad y luego, la búsqueda de controles en uno y otro sentido. 
Erika Pani, por su parte, incorpora dos grandes temas que solo aparecen marginalmente en el libro, pero que sin duda ocupan un lugar decisivo en la dinámica política del período: el congreso y las constituciones. Podríamos seguir agregando cuestiones "que no están" pero que en una historia más integral de la política en las repúblicas no podrían faltar.

\section{Una cuestión insoslayable}

No puedo obviar, sin embargo, una ausencia varias veces advertida por mis comentaristas. Me refiero a la problemática del papel del catolicismo, la Iglesia o la religión en esta historia, que se aborda desde tres registros diferentes. Por una parte, y recuperando una conocida y sugerente proposición de Antonio Annino, Darío Roldán se interroga por el lugar de la tradición católica en la conformación del republicanismo hispánico, en contraste con el de raigambre anglo-sajona, y remite así a la matriz ideológico-cultural -por decirlo simplificadamente- que habría permeado las experiencias hispanoamericanas aun después de su ruptura con España. Esa "originalidad" de la región también aparece en las consideraciones de Sol Serrano, pero en clave político-institucional.En el proceso de secularización que siguió a las independencias, nos dice,estas repúblicas no fueron inicialmente "contra la Iglesia... sino propiamente contra la monarquía y con ello se disolvió el vínculo entre monarquía y catolicismo..." y dio paso al proceso mayormente negociado de "laicización del Estado" que se resolvió en general "con mucha menor violencia que otros casos europeos". Gutiérrez Ardila, en cambio, ve en el papel de la religión y de la Iglesia católica en la vida pública una cuestión "que caldeó como ninguna otra los debates políticos" y que, por lo tanto, habría alimentado la volatilidad política. Nuevamente aparece aquí, como en el comentario de Roldán, el contraste con el caso estadounidense.

Cada uno de estos puntos amerita un tratamiento particular que no podría encarar aquí. En cambio, y respondiendo a una pregunta que los engloba y que aparece explícitamente formulada en un par de casos, voy a referirme al porqué de la escasa presencia de estos temas en el libro. No tengo dudas de la importancia tanto del catolicismo como matriz ideológico-cultural de las derivas poscoloniales hispanoamericanas, como de la religión en la organización social y de la Iglesia en el entramado institucional y político de las naciones en formación. Tampoco se me pasó por alto el impacto que la ruptura del ordenamiento colonial y la afirmación de las nuevas soberanías tuvieron en las relaciones entre los poderes de las flamantes repúblicas y una Iglesia que ya no era una con el poder político como lo había sido en la monarquía sino que aparecía desgajada de las instituciones estatales en formación. Ese proceso de secularización, de diferenciación entre poder religioso y poder político traería -como analiza con maestría Roberto di Stefano para el Río de la Plata- conflictos intensos y negociaciones para dirimir espacios y jurisdicciones en el nuevo orden republicano. El lugar de la Iglesia, entonces, pasó a ser motivo de disputas, como lo fue también el papel de la religión en la organización social; ambas cuestiones alimentaron la conflictividad política de todo el siglo XIX, con diferente intensidad según las épocas y las regiones. 
Todos estos procesos fueron parte decisiva de la construcción republicana, pero tuvieron una incidencia más bien lateral sobre los planos específicos en que focalicé mi estudio. Hay dos facetas de esta vasta problemática, en cambio, que sí podemos vincular directamente con mis preocupaciones centrales. La primera refiere a la presencia concreta de la Iglesia -como institución de autonomía inestable en relación con el poder político- y de miembros del clero, tanto regular como secular, en la acción política. Por ello, en el libro hago mención, aquí y allá -como señala Serrano- a la participación de clérigos en diferentes instancias del sistema representativo, pues desde temprano se sumaron desde posiciones diversas a las lides electorales, a las acciones armadas y a las variadas manifestaciones de la opinión pública. La institución, por su parte, no se privó de tomar partido a la hora de los enfrentamientos entre grupos políticos, buscando incidir en las disputas entre civiles en los marcos de la república representativa. Quizá el ejemplo más generalizable en ese sentido sea el de la prensa, pues en toda la región podemos encontrar periódicos directamente vinculados a la Iglesia oficial de cada lugar, productos orgánicos de la institución que buscaba así crear opinión e influir en la vida política.

Una segunda faceta muy relevante remite a la cuestión del origen del poder en estas repúblicas seculares. Al entender el poder como una construcción humana, despojada de referencias trascendentes, el pueblo pasó a considerarse la primera y la última instancia en la institución de la comunidad política y en la fundación de la autoridad. Pero esta ausencia de fundamentos trascendentes, abría el espacio a la incertidumbre propia de la política moderna, pues -y aquí me disculpo por citarme textualmente- "lo que el pueblo decidía construir también podía desmantelar" (p. 228). Ese dilema estuvo en la base, sostengo en el libro, de la inestabilidad de estas (y otras) repúblicas y llevó a las dirigencias de distinto signo a ensayar diferentes soluciones para doblegarla, que siempre resultaron insuficientes, parciales, efímeras. En ese marco, en más de un caso se apeló a la religión (católica) para dotar de un basamento trascendente a la comunidad política y se recurrió a ella como fundamento doctrinario o, más frecuentemente, como fuente de rituales y ceremonias que se recuperaban para contribuir al arraigo de las nuevas liturgias. Pero en la mayoría de los casos, las propuestas de reponer a la religión como última ratio de la república tuvieron éxitos solo puntuales y de corto alcance, frente al predominio de la secularización del poder y de sus fundamentos. Finalmente, la inestabilidad y la incertidumbre continuaron marcando la vida política, al menos hasta el último cuarto del siglo XIX.

\section{Lo que vino después}

La última afirmación toca un tema presente en todos los comentarios, el del fin del "experimento republicano" tal y como se desenvolvió a lo largo de más de cinco décadas a partir de las independencias. No hay objeciones respecto al punto de partida -los años 20- pero sí preguntas acerca del momento en que postulo un cambio de rumbo en la vida política de estas repúblicas, que habría marcado el 
fin de una época. Me detengo, en particular, en las observaciones de Erika Pani y Darío Roldán, quienes plantean más directamente esa cuestión. Para la primera, "la transición... a la república de fin de siglo resulta a un tiempo intrigante y desconcertante", que la lleva a formular un interrogante fundamental: si "(l) as críticas al (des)orden de las cosas no eran nuevas como no lo era tampoco la preocupación 'por la inestabilidad política' (p.200). ¿Cómo se volvieron, en algún momento, estas más apremiantes y aquellas más convincentes?”. Roldán, por su parte, se pregunta “¿En qué sentido, la república que, como tal, siguió existiendo, fue desplazada?” y, por lo tanto, “cómo comprender el 'final' de la República”.

Una vez más, no voy a intentar responder puntualmente a estos desafíos, sino apenas desgranar algunas ideas que ellos me suscitan. Y empiezo por el principio, esto es, por la instauración de la república como, en palabras de Roldán, "dispositivo institucional" en la constitución de las nuevas comunidades que surgieron en la década de 1820 después de las independencias. Ese camino no era el único posible, sino que resultó del triunfo político de una forma de organización por sobre otras disponibles que fueron derrotadas y que, salvo excepciones puntuales, nunca recuperaron protagonismo. No había un solo formato de república y lo que siguió, como se enfatiza en el libro, fue una historia de repúblicas en plural. En ese mundo heterogéneo detecté -creí detectar- patrones y tendencias comunes de organización y funcionamiento en instituciones, normas y prácticas que materializaban el principio de la soberanía popular y constituían el motor del sistema representativo de gobierno. Con variaciones importantes en el tiempo y en el espacio, registro sin embargo algunas constantes que me permiten hablar de un "experimento" político en singular, que se habría ido reproduciendo durante más de cinco décadas. El signo distintivo de esas repúblicas no habría sido, sin embargo, el republicanismo como matriz ideológica -pues encuentro que esta tradición se combinaba con otras en lenguajes políticos variables a lo largo del siglo-, sino un patrón de relaciones entre pueblo y gobierno que, aunque cambiantes, imprimieron ciertos rasgos propios a esa experiencia.

Pero hacia 1880, en la mayoría de las nuevas naciones, observo un cambio que afectaba lo que a mi entender constituían pilares de ese ordenamiento político, tanto en materia de principios como de instituciones y prácticas. Ese viraje estaba destinado a combatir la incertidumbre y la inestabilidad que habían caracterizado la vida republicana hasta entonces, y a satisfacer una demanda de disciplinamiento que venía de larga data pero solo en esos años logró imponerse. No se trató de un tránsito gradual impulsado por las transformaciones más generales de la sociedad, la economía y la cultura del momento, sino de un triunfo político -tal como lo había sido la instauración de la república en los 20- de quienes propendían a un nuevo orden por sobre aquellos que seguían defendiendo lo ya conocido. La presión por ese cambio venía de antes, pero fue en sede política donde en la mayoría de las naciones de la región se decidió la partida, que por cierto podría haber tenido otros desenlaces. En el libro aventuro, además, que otras repúblicas de esa era -en Brasil y en Francia, por ejemplo- se diseñaron siguiendo un libreto semejante. 
Hay un último punto que plantea Roldán que me gustaría retomar. Cito sus palabras en aras de la precisión: "ese final [el del experimento republicano] parece haber estado de alguna manera relacionado con un conjunto de reclamos y propuestas que 'ya no se hacían en clave republicana'; al contrario, eran impulsados por los 'ideales del socialismo y las teorías de la democracia' (p. 222). En realidad, lo que concluyo en el libro es que la república en su reciente formato finisecular ("domesticada", diría para simplificar) pronto encontró resistencias por parte de "fuerzas políticas y sociales emergentes" que empezaron a cuestionar ese modelo, ya no exigiendo volver al viejo (des)orden (retomo la expresión de Pani), sino invocando nuevos ideales, de sesgo democrático y tintes socialistas. En ese sentido, no encuentro una relación directa entre estas tormentas del cambio de siglo y el ocaso del "experimento republicano" -que había predominado en décadas anteriores pero que ya para entonces había quedado atrás-.

Queda pendiente, de todas maneras, el desafío de entender la relación entre república (en sus diferentes encarnaciones) y democracia, un tema que evité cuidadosamente en mi libro, pero que no deja de constituir un núcleo problemático clave a la hora de dar cuenta de los debates políticos del siglo XIX y, muy especialmente, de lo que vino después. Quedo así en deuda con mis generosos interlocutores, con Darío pero también con Erika, Sol y Daniel, por lo que espero que esta intervención sea tan solo una estación en el productivo intercambio que venimos manteniendo desde hace años y que estoy segura habremos de seguir sosteniendo en el futuro. 


\section{Q Bibliografía}

" Thibaud, C. (2019). Para una historia policéntrica de los republicanismos atlánticos (17701889), Primas, 23, pp.145-162. 